www.jmscr.igmpublication.org

Index Copernicus Value: 79.54

ISSN (e)-2347-176x ISSN (p) 2455-0450

crossref DOI: https://dx.doi.org/10.18535/jmscr/v7i6.175

Journal Of Medical Science And Clinical Research

IGM Publication

An Official Publication of IGM Publication

\title{
Assessment of Migraine Disability of Migraine Patients Using Migraine Specific Disability Assessment Scale (MIDAS)
}

\author{
Authors \\ Dr Md. Nazmuz Zaman Palash ${ }^{1 *}$, Dr Ram K. Saha ${ }^{2}$, Dr Mahbubul Hakim Mishu ${ }^{3}$, \\ Dr Prianka Das ${ }^{4}$, Dr Mohammad Adnan Jahan ${ }^{5}$ \\ ${ }^{1}$ MBBS, DU, MPH, National Institute of Preventive and Social Medicine (NIPSOM), Medical Officer, \\ Neurology Department, BSMMU, Dhaka, Bangladesh \\ ${ }^{2}$ M.D., Neurology, Vascular Neurology Fellow, Thomas Jefarson University Hospital, USA \\ ${ }^{3}$ MBBS, MD (In Course), Medical Officer, Neurology Department, BSMMU, Dhaka, Bangladesh \\ ${ }^{4}$ MBBS, MPH, National Institute of Preventive and Social Medicine (NIPSOM), Dhaka, Bangladesh \\ ${ }^{5}$ MBBS, MPH, BCS (Health), National Institute of Preventive and Social Medicine (NIPSOM), Dhaka, \\ Bangladesh \\ *Corresponding Author \\ Dr Md. Nazmuz Zaman Palash
}

\begin{abstract}
Background: Headache is a standout amongst the most disabling disorders on the planet with a high score of DALY. Hence, evaluation of the disability in headache patients is vital for both the patient and the doctor in order to decide malady seriousness and to pick suitable treatment. A few instruments have been created lately to survey the functional results of migraine, one of which is MIDAS scale.

Objective: The main aim of this study is to assess migraine disability of migraine patients using migraine specific disability assessment scale (MIDAS).

Method: To do so, across sectional research was conducted on al headache clinic named Bangabandhu Sheikh Mujib Medical University, Dhak, a on 220 patients scheduled for visitation regarding their migraine symptoms. The study duration was almost two years from the August 2018 to January 2019.

Results: In the present investigation, the results showed that the general MIDAS score was fairly high with the mean score of $20.11 \pm 8.08$. As per the MIDAS score very nearly $60 \%$ of the respondents were ordered as having severe disability at $58.2 \%$, trailed by around one-fourth had moderate disability at $25 \%$. Just $10.0 \%$ was distinguished as meager to mild disability.

Conclusion: Related studies show that most of the people have suffered from headache related complexities at least at one point of their lives which is in tune with the findings of the study. Thusly it is prudent to continuously conduct extensive research on migraine related problems to create or practice better treatment plan.
\end{abstract}

Keywords: Migraine, MIDAS Scale, Quality of Life, MSQ score.

\section{Introduction}

World Health Organization (WHO) characterized

Disability Djusted Life Years (DALY), as a significant pointer of incapacity. Headache is a standout amongst the most disabling disorders on the planet with a high score of DALY. Hence, 
evaluation of the disability in headache patients is vital for both the patient and the doctor in order to decide malady seriousness and to pick suitable treatment. ${ }^{1}$ A few instruments have been created lately to survey the functional results of migraine: the Henry Ford Hospital Headache Disability Inventory (HDI), the Headache Impact Questionnaire (HIQ), the Chronic Pain Index (CPI), the Migraine Disability Assessment (MIDAS) questionnaire; Medical Outcome StudyShort Form (SF-36), Migraine Therapy Assessment (MTAQ) questionnaire, and the HIT6, a questionnaire got from the Headache Impact Test (HIT-DynHA) accessible on the Internet. ${ }^{1}$ Headache can contrarily affect significant connections, with about portion of migraineurs announcing harm to an association with an accomplice or life partner from migraines. An ongoing overview of 1466 grown-ups with headache, $56 \%$ revealed an association with a mate or accomplice had been harmed because of headaches, with $6 \%$ detailing headache adding to a break-up with a life partner or spouse.

Thusly, lessening the weight of this disabling condition ought to be an undeniable social insurance mediation target. Broadening this methodology, the migraine disability assessment (MIDAS) questionnaire estimates lost time because of headache in three areas: work, family social and leisure activities, as well as household work and chores. Proportions of lost time are all the more promptly converted into economic terms since absenteeism diminished productivity at work are the central determinants of the expense of illness. $^{2}$ When all is said in done, upgrades in wellbeing status convert into increments in HRQoL and decreases of disability. Incapacity scores and HRQoL keep running in the other direction.

\section{Objectives \\ Main Objective}

The main aim of this study is to assess migraine disability of migraine patients using migraine specific disability assessment scale (MIDAS).

\section{Specific Objectives}

The specific objectives of the study are:

- Identifying the varying grades of migraineurs,

- Gauging the quality of life of the respondents,

- Comparing the disability level with the patients quality of life.

\section{Method}

\section{Study Type}

This study is conducted using cross sectional method.

\section{Criteria Specified for the Study}

\begin{tabular}{|c|c|}
\hline Inclusion Criteria \\
\hline$\bullet$ & Patients are of clinically sound mind \\
\hline - & $\begin{array}{l}\text { Patients came to the clinic to get appropriate } \\
\text { treatment for Migraine }\end{array}$ \\
\hline & $\begin{array}{l}\text { Patients have the capacity to sign the form of } \\
\text { consent }\end{array}$ \\
\hline Exclusion Criteria \\
\hline $\begin{array}{l}\text { The reasons for the migraine is due to some } \\
\text { other physiological complexity }\end{array}$ \\
\hline - & Patients abusing illegal drugs \\
\hline & Patients who have psychological problems \\
\hline
\end{tabular}

\section{Study Area}

- A headache clinic named Bangabandhu Sheikh Mujib Medical University, Dhaka was chosen for this study

- 220 patients scheduled for appraisal of their problems regarding migraine

- The study was conducted for almost two years from the August 2018 to January 2019.

\section{Study Procedure}

The study procedure that followed for this study was, at first, the patients of the study were asked to be the part of the study. Second, the level or grade of the migraine was identified among the patients was appraised using Midas Scale. Third, a survey was conducted on their quality of life, and finally, a comparative analysis was done with Midas and MSQ score.

\section{Sampling technique}

Headache clinic, Bangabandhu Sheikh Mujib Medical University, Dhaka selected 220 sample 
purposively. Participants were selected in the headache clinic who attended for outdoor consultation in BSMMU and collecting the information about the disability and quality of life among known case of migraine.

\section{Research approach}

After getting approval of the research proposal from the respected faculty members of NIPSOM, ethical clearance was taken from institutional Ethical Review Committee. A consent form was prepared containing detail information about the study including study objectives, procedure of data collection, risk and benefits to the participants. After taking written informed consent, data were collected from the participants.

\section{Data processing and analysis}

Data analysis began with SPSS 21 analysis. Means and standard deviations were calculated for continuous variables while frequencies and percentages were calculated for categorical variables, simultaneously to see the relationship and statistical significance Chi-Square test, ANOVA test and Pearson product-moment correlation test done.

\section{Results}

In accordance to the MIDAS score almost sixty percent of the respondents were classified as having severe disability (58.2\%), followed by those who were categorized as having moderate disability (25.0\%). Only $10.0 \%$ was identified as little to mild disability (Table 1).

Table 1: Migraine Disability- MIDAS score

\begin{tabular}{|c|c|c|}
\hline MIDAS Grade & $\begin{array}{c}\text { Number of } \\
\text { Patients }\end{array}$ & Percentage \\
\hline $\begin{array}{l}\text { Grade I (Little or } \\
\text { Disability) }\end{array}$ & 15 & 6.8 \\
\hline Grade II (Mild Disability) & 22 & 10.0 \\
\hline $\begin{array}{l}\text { Grade III (Moderate } \\
\text { Disability) }\end{array}$ & 55 & 25.0 \\
\hline Grade IV (Severe Disability) & 128 & 58.2 \\
\hline Total & 220 & 100.0 \\
\hline
\end{tabular}

Figure 1 shows the distribution of MIDAS score in histogram. The mean score was $20.11 \pm 8.08$.

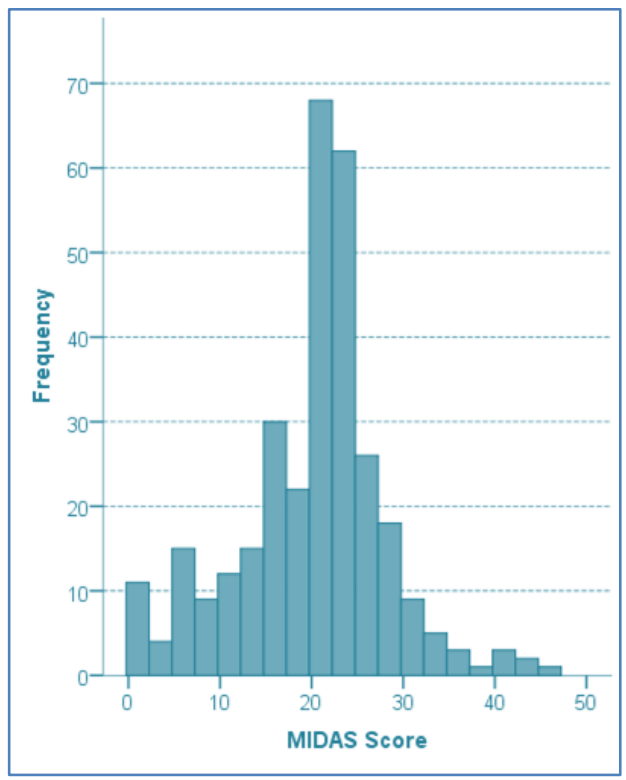

Figure 1: Distribution of MIDAS ScoreRespondents $(\mathrm{n}=300)$

The migraine specific quality of life or MSQ score is demonstrated in table 2. The overall mean or average score was $54.4 \pm 9.9$. The mean MSQ score of role restrictive (RR), role preventive (RP) and emotional function (EF) was $57.4 \pm 8.9,54.4$ \pm 12.1 and $48.0 \pm 18.6$, respectively.

Table 2: Migraine Specific Quality of Life

\begin{tabular}{lccc}
\hline MSQ score & Minimum & Maximum & Mean \pm SD \\
\hline $\begin{array}{l}\text { Role function }- \\
\text { restrictive }\end{array}$ & 26 & 80 & $57.4 \pm 8.9$ \\
$\begin{array}{l}\text { Role function- } \\
\text { preventive }\end{array}$ & 15 & 80 & $54.4 \pm 12.1$ \\
$\begin{array}{l}\text { Emotional } \\
\text { function }\end{array}$ & 0 & 100 & $48.0 \pm 18.6$ \\
Total & 21 & 81 & $54.5 \pm 9.8$ \\
\hline
\end{tabular}

The MSQ role restrictive scale score increased with the increase of MIDAS disability score. There was significant positive correlation between migraine disability and role restrictive function of migraine specific quality of life $(r=0.247$, $\mathrm{p}<0.001)$ which showed a correlation between migraine disability and role preventive (RP) function of migraine specific quality of life $(\mathrm{r}=0.204, \mathrm{p}<0.001)$. (Figure 2) 


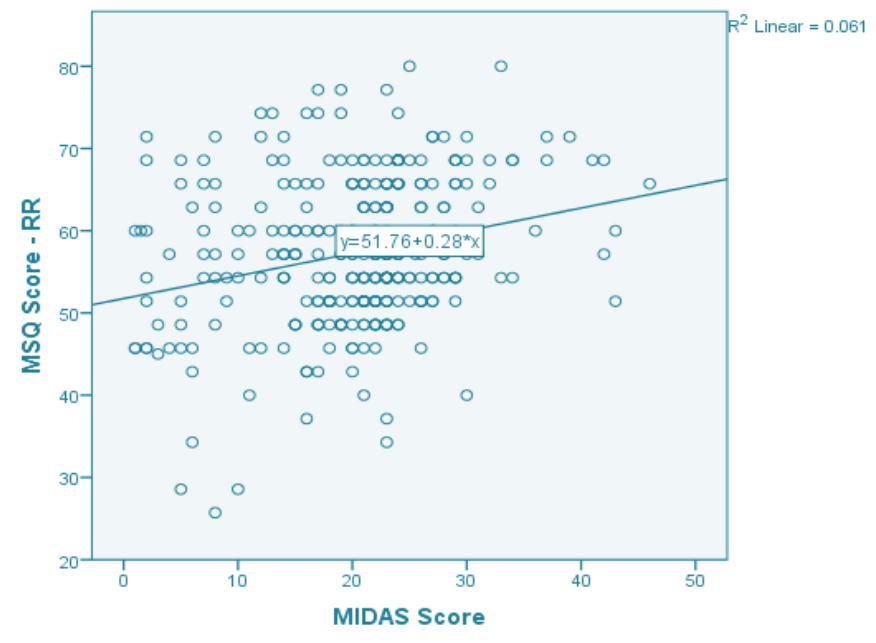

Figure 2: Migraine Disability (Midas) and MSQ Role Restrictive Scale Score

\section{Discussion}

The MIDAS questionnaire is the most broadly examined instrument. ${ }^{3-6}$ MIDAS catches headache related disability in all life spaces over a 3-month time span. It contains just seven inquiries and has simple and intuitive scoring rules.

In the present investigation, the general MIDAS score was fairly high with the mean score of $20.11 \pm 8.08$. As per the MIDAS score very nearly $60 \%$ of the respondents were ordered as having severe disability at $58.2 \%$, trailed by around onefourth had moderate disability at $25 \%$. just $10.0 \%$ was distinguished as meager to mild disability. This is genuinely like the investigation directed by Domenico D'Amico et al., displayed the circulation of disability grades: GRADE I (minimal or infrequent), 13.3\%; GRADE II (mild or infrequent), 13.6\%; GRADE III (moderate disability), 26.1\%; And GRADE IV (severe disability), 47\%. The general MIDAS score was 23.4 (SD=17.55; median, 19). ${ }^{1}$

The MSQ score can be viewed as a pointer of headache seriousness self-revealed by the patients, evaluating the most disabling effect of migraine in day by day life. The general mean score as per migraine specific quality of life was $54.4 \pm 9.8$. The mean MSQ score of Role Restrictive (RR), Role Preventive (RP), and Emotional Function (EF) was $57.4 \pm 8.9,54.4 \pm 12.1$ and $48.0 \pm 18.6$, individually. The examination approving migraine specific quality of life questionnaire in episodic and chronic migraine pitched comparable results with MSQ domain scores for $\mathrm{CM}$ and $\mathrm{EM}$ gatherings, separately, were: $\mathrm{RP}=61.4 \pm 26.1$ and $71.7 \pm 24.0 ; \mathrm{RR}=44.4 \pm 22.1$ and $56.5 \pm 24.1 ; \mathrm{EF}$ $=48.3 \pm 28.1$ and $67.2 \pm 26.7 .^{7}$ Internal coherence of the general example for RP, RR, and EF was $0.90,0.96$, and 0.87 , respectively. ${ }^{7}$

Be that as it may, the MSQ RR scale score expanded with the expansion of MIDAS disability score. There was significant positive correlation between migraine disability and role restrictive function of headache explicit personal satisfaction $(\mathrm{r}=0.247, \mathrm{p}<0.001)$.The MSQ RP scale score expanded with the expansion of MIDAS disability score. There was significant positive correlation between migraine disability and RP function of migraine specific quality of life $(r=0.204$, $\mathrm{p}<0.001)$. The MSQ EF score had positive correlation with MIDAS disability score.

\section{Conclusion}

The result part of the study shows that majority of the migraineurs suffers from severe and painful migraine. Not only so, related studies show that most of the people have suffered from headache related complexities at least at one point of their lives. Thusly it is prudent to continuously conduct extensive research on migraine related problems to create or practice better treatment plan.

\section{References}

1. D'amico, D. \& Bussone, G. 2003. Disability and migraine: recent outcomes using an Italian version of MIDAS. The journal of headache and pain, 4, s42-s46.

2. $\mathrm{Hu}, \mathrm{X} . \mathrm{H} .$, Markson, L. E., Lipton, R. B., Stewart, W. F. \& Berger, M. L. 1999. Burden of migraine in the United States: disability and economic costs. Archives of internal medicine, 159, 813-818.

3. Stewart, W., Lipton, R. \& Simon, D. 1996. Work-related disability: Results from the American migraine study. Cephalalgia, 16, 231-238. 
4. Stewart, W. F., Lipton, R. B., Dowson, A. J. \& Sawyer, J. 2001. Development and testing of the Migraine Disability Assessment (MIDAS) Questionnaire to assess headache-related disability. Neurology, 56, S20-S28.

5. Stewart, W. F., Lipton, R. B., Kolodner, K. B., Sawyer, J., Lee, C. \& Liberman, J. N. 2000. Validity of the Migraine Disability Assessment (MIDAS) score in comparison to a diary-based measure in a population sample of migraine sufferers. Pain, 88, 41-52.

6. Stewart, W. F., Roy, J. \& Lipton, R. B. 2013. Migraine prevalence, socioeconomic status, and social causation. Neurology, 10.1212/WNL. 0b013e3182a43b32.

7. Bagley, C. L., Rendas-Baum, R., Maglinte, G. A., Yang, M., Varon, S. F., Lee, J. \& Kosinski, M. 2012. Validating migraine-specific quality of life questionnaire v2. 1 in episodic and chronic migraine. Headache: The Journal of Head and Face Pain, 52, 409-421. 